\title{
A nanoliposome delivery system to synergistically trigger TLR4 AND TLR7
}

\author{
Christopher B Fox', Sandra J Sivananthan', Malcolm S Duthie', Julie Vergara', Jeffrey A Guderian', Elliot Moon², \\ David Coblentz ${ }^{2}$, Steven $\mathrm{G}$ Reed ${ }^{1}$ and Darrick Carter ${ }^{1,3^{*}}$
}

\begin{abstract}
Background: Recent reports that TLR4 and TLR7 ligands can synergistically trigger Th1 biased immune responses suggest that an adjuvant that contains both ligands would be an excellent candidate for co-administration with vaccine antigens for which heavily Th1 biased responses are desired. Ligands of each of these TLRs generally have disparate biochemical properties, however, and straightforward co-formulation may represent an obstacle.

Results: We show here that the TLR7 ligand, imiquimod, and the TLR4 ligand, GLA, synergistically trigger responses in human whole blood. We combined these ligands in an anionic liposomal formulation where the TLR7 ligand is in the interior of the liposome and the TLR4 ligand intercalates into the lipid bilayer. The new liposomal formulations are stable for at least a year and have an attractive average particle size of around $140 \mathrm{~nm}$ allowing sterile filtration. The synergistic adjuvant biases away from Th2 responses, as seen by significantly reduced IL-5 and enhanced interferon gamma production upon antigen-specific stimulation of cells from immunized mice, than any of the liposomal formulations with only one TLR agonist. Qualitative alterations in antibody responses in mice demonstrate that the adjuvant enhances Th1 adaptive immune responses above any adjuvant containing only a single TLR ligand as well.
\end{abstract}

Conclusion: We now have a manufacturable, synergistic TLR4/TLR7 adjuvant that is made with excipients and agonists that are pharmaceutically acceptable and will have a straightforward path into human clinical trials.

Keywords: TLR4, TLR7, Synergy, Adjuvant, Manufacturability, Liposome

\section{Background}

Modern, effective vaccines rely on a combination of a purified antigen against which an immune response is desired and an adjuvant that triggers the innate immune system to enhance the magnitude and quality of the generated immune response [1]. Producing new adjuvants that can direct appropriate immunity is therefore becoming key to vaccine design and groups have shown that even in the context of the same antigen different outcomes are achieved as a function of the co-administered adjuvant [2]. Recent commercial approval of the Cervarix ${ }^{\circledR}$ vaccine that contains MPL, a defined TLR4 ligand, has added momentum to the development of a new generation of adjuvants [3].

\footnotetext{
* Correspondence: dcarter@idri.org

${ }^{1}$ Infectious Disease Research Institute (IDRI), Seattle, WA, USA

${ }^{3}$ PAI Life Sciences, 1616 Eastlake Ave E Suite 500, Seattle 98102 WA, USA

Full list of author information is available at the end of the article
}

The immune system has the inborn ability to recognize molecular signatures carried by microbes. These Microbe Associated Molecular Patterns (MAMPs) trigger any of an array of receptor sensors in cells to alert the organism and mobilize an appropriate immune response. MAMPs are generally molecules that are vital to the microbe, performing key functions, but are not found in the host. Examples include: lipopolysaccharides (LPS) found on the surface of gram negative bacteria [4], RNAs produced as part of viral replication [5], and flagellins that make up bacterial flagella [6].

The Toll-Like Receptor (TLR) family of proteins is a well characterized group of innate signaling receptors that respond to a variety of MAMPs. TLRs 1,2 , and 6 heterodimerize and respond to lipopeptides; TLR3 binds double stranded RNAs; TLR4 signals when triggered by LPSs; TLR5 senses flagellins; TLR7 and 8 detect single stranded RNAs and TLR9 responds to DNA with CpG motifs [5,7-12]. To augment their ability to appropriately detect 
pathogens, the TLRs are partitioned where the likely source of the MAMP would be found; i.e. shed LPS is picked up by lipopolysaccharide binding protein and transported to the cell membrane where TLR4 is located and the viral RNA sensors TLR3, 7, and 8 are located in endosomes inside the cell where viral RNAs would be produced and their detection required [13,14].

TLR signaling and the resulting innate and adaptive responses can be enhanced by synergy within the TLR family [15] or by signals from TLR combined with those from non-TLR innate sensors $[16,17]$. Within the TLR family, TLR4 and TLR7 have been targeted by agonists that are in late stage development $[18,19]$ or are commercial $[20,21]$ and the two TLR show potential for powerful synergism. This can be seen in increased magnitudes of cytokine secretion, enhanced germinal center formation, class switching and antibody diversity [22,23]. While the synergy that is induced is dramatic, the agonists have to be co-localized and efforts to develop such a combination adjuvant that can be manufactured cost effectively at scale are still needed. Researchers in academic and company settings have started to produce adjuvants and vaccine nanoparticles that contain multiple innate ligands [22,24-26] and standard vaccine preparations usually contain several TLR ligands since they are derived from inactivated pathogens $[27,28]$, but most of these attempts are proof of concept exercises that have not progressed due to the cost of manufacturing or the poor definition of the relative ligand content. We report here the development of a nanoliposome that colocalizes TLR4 and TLR7 agonists and synergistically enhances immune responses. The process used for manufacture of the combination can be scalable and commercially viable like similar liposomal formulations.

\section{Results}

In vitro synergy of GLA and IMQ

To demonstrate that the selected ligands would synergize, admixtures of the TLR7 agonist IMQ and the TLR4 agonist GLA were suspended in an aqueous formulation and various dilutions tested for the ability to elicit cytokine secretion from human whole blood. Although IMQ itself is essentially insoluble in water, a proprietary composition by Invivogen facilitates aqueous suspension [29] and, because both agonists act on the same cells, there is no need for co-delivery in vitro. As shown in Figure 1, the molecules synergistically elicit secretion of IL12p70 and IFN $\gamma$ from cells. IL8 and MIP- $1 \beta$ were also determined and demonstrated enhanced secretion in the combination group compared to the single ligands alone. These data demonstrate that when the same cells are stimulated by both ligands, synergistic signaling by the innate immune system can occur.

\section{Manufacturing of the synergistic nanoliposome}

After establishing that the molecules have the potential for synergistic signaling, we set out to develop a manufacturing process that would allow them to be co-localized in the same particle. Liposomes comprise a versatile formulation platform since they can be used to bring together active molecules with different structural properties. For instance, lipidic molecules such as MPL ${ }^{\circledR}$ or GLA can be incorporated in the phospholipid bilayer whereas small, more soluble molecules may be encapsulated in the aqueous core. Furthermore, several liposome-based formulations have been approved for human use or reached advanced clinical development in existing vaccine (e.g. Epaxal ${ }^{\circ}$, Mosquirix) and drug (e.g. Ambisome ${ }^{\circ}$ ) products. Finally, liposomes can be manufactured at small diameter $(<200 \mathrm{~nm})$, permitting terminal sterile filtration and improved lymph node targeting [30].

The formulation of IMQ presents a particular challenge due to its insolubility in aqueous solutions at physiological $\mathrm{pH}[31,32]$. In fact, IMQ has very low solubility in most organic solvents, with the exception of fatty acids which form the basis of the approved topical cream containing IMQ called Aldara [31]. IMQ is soluble in acidic aqueous solutions and $0.1 \mathrm{M}$ lactic acidbased formulations of IMQ are in clinical development for the treatment of bladder cancer [32-34]. Although lactic acid is a widely used pharmaceutical excipient [32,35], it does not prevent the systemic distribution of IMQ; therefore, improving its vaccine adjuvant properties requires further formulation techniques to localize the molecule in the body after administration [32,36]. We hypothesized that liposomes with a lactic acid core would facilitate encapsulation of soluble IMQ while enabling the bulk aqueous phase external to the liposomes to maintain a physiological buffer at close to a neutral $\mathrm{pH}$, which is desirable to minimize injection pain [37]. Moreover, liposomes should allow the intercalation of the six acyl chains of GLA into the lipid bilayer.

Liposomes were manufactured using a thin-film method wherein phospholipids and GLA were mixed with cholesterol in organic solvent followed by evaporation of the solvent under vacuum. Liposomes were rehydrated in $100 \mathrm{mM}$ lactic acid containing $10 \mathrm{mg} / \mathrm{ml} \mathrm{IMQ}$, and sonicated in a water bath at $\sim 60^{\circ} \mathrm{C}$ (above the phase transition temperatures of the lipids) for $\sim 1.5-3 \mathrm{hrs}$. The liposomes were then transferred to a desalting column and the external lactic acid solution was exchanged for phosphatebuffered saline (PBS) at pH 7.2.

Different phospholipid compositions previously developed in our lab for formulation of GLA [38] were evaluated as an initial formulation screen (Table 1), including an anionic liposome (DPPC, DPPG, cholesterol; 18:2:5 weight ratio), a cationic liposome (DPPC, DPTAP, cholesterol; 18:2:5 weight ratio), and a neutral liposome (DOPC, 

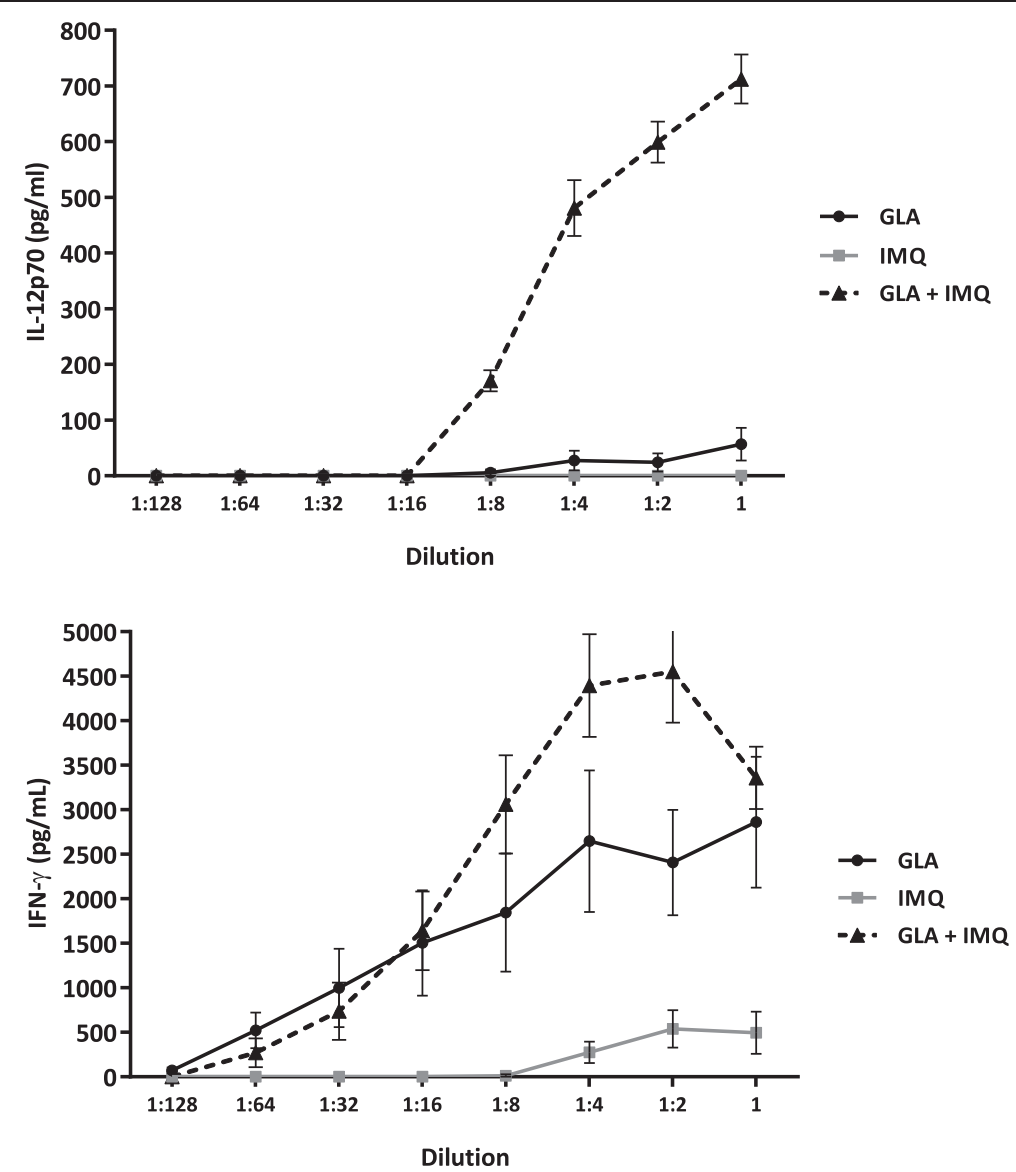

Figure 1 Synergy between GLA and IMQ in vitro. Human whole blood was incubated with $2 \mu \mathrm{g} / \mathrm{mL}$ of GLA and $8 \mu \mathrm{g} / \mathrm{mL}$ of IMQ either alone or in combination; the amount of secreted IL12p70 (top panel) or IFNY (bottom panel) were then determined by ELISA. Means and standard error of three donor values are shown. Similar trends were seen for MIP1 $\beta$ and IL8 as well (data not presented).

cholesterol; 20:5 weight ratio). Total DPPC or DOPC concentrations were estimated at 50 and $55 \mathrm{mg} / \mathrm{ml}$, respectively, assuming no extra loss in the buffer exchange and filtration steps. The cationic liposomes showed lower encapsulation efficiency. Precipitation was evident in the neutral DOPC-based liposomes and substantial IMQ was lost upon filtration through a $0.2-\mu \mathrm{m}$ membrane, even though average particle size was small and encapsulation efficiency was high. The anionic liposomes also showed comparatively high encapsulation efficiency and much less tendency for precipitation over time. The loss in IMQ concentration upon filtration may represent the proportion of liposomes that are larger than $200 \mathrm{~nm}$ and not able to pass through the membrane. Particle size and IMQ concentration in three additional anionic liposome batches prepared at a concentration of $38 \mathrm{mg} / \mathrm{ml}$ DPPC and stored at $5^{\circ} \mathrm{C}$ demonstrated only $7 \pm 5 \%$ and $9 \pm 1 \%$ change in particle size and IMQ concentration, respectively, at the 12-month timepoint compared to immediately after manufacture. Finally, one of these three batches also contained GLA, and its concentration changed only $\sim 8 \%$ over 12 months. Therefore, the

Table 1 Liposome formulation screen for encapsulation of IMQ

\begin{tabular}{|c|c|c|c|c|c|c|c|}
\hline $\begin{array}{l}\text { Liposome } \\
\text { type }\end{array}$ & Composition & $\begin{array}{c}\text { Number of } \\
\text { batches }\end{array}$ & $\begin{array}{l}\text { IMQ concentration } \\
(\mathrm{mg} / \mathrm{ml})\end{array}$ & $\begin{array}{l}\text { IMQ loading } \\
\text { efficiency (\%) }\end{array}$ & $\begin{array}{l}\% \text { Loss after } 0.2-\mu \mathrm{m} \\
\text { filtration }\end{array}$ & $\begin{array}{l}\text { Particle size } \\
\text { (Zave, nm) }\end{array}$ & $\begin{array}{c}\text { Polydispersity } \\
\text { index }\end{array}$ \\
\hline Anionic & DPPC/DPPG/Cholesterol* & 8 & $0.6 \pm 0.1$ & $6 \pm 1$ & $23 \pm 12$ & $151 \pm 20$ & $0.17 \pm 0.07$ \\
\hline Cationic & DPPC/DPTAP/Cholesterol & 1 & 0 & 0 & NM & 64 & 0.07 \\
\hline Neutral & DOPC/Cholesterol* & 4 & $0.7 \pm 0.2$ & $7 \pm 2$ & $45 \pm 22$ & $73 \pm 23$ & $0.20 \pm 0.01$ \\
\hline
\end{tabular}

*Some batches also contained GLA, although the presence of GLA did not have a significant effect on the reported IMQ loading efficiency or the other properties mentioned. NM: not measured. 
anionic liposomes consisting of DPPC, DPPG, and cholesterol were selected as the most suitable formulation for a synergistic adjuvant containing GLA and IMQ.

\section{Biophysical characterization of the liposome}

Due to the insolubility of IMQ in aqueous solutions near neutral $\mathrm{pH}$, it was thought that the IMQ should be localized in the acidic interior of the liposomes. We first sought to confirm that the external lactic acid was removed by the desalting column treatment by measuring $\mathrm{pH}$ values before and after exposure to the desalting column in liposomes containing IMQ, GLA, both of the agonists, or neither. The $\mathrm{pH}$ values prior to buffer exchange ranged from $2.5-3.5$, whereas $\mathrm{pH}$ values after buffer exchange were $6.7-6.9$ (Table 2), indicating that the lactic acid solution had indeed been replaced with the buffered saline, although the $\mathrm{pH}$ values had gradually decreased by an average of $\sim 0.4$ units when measured one month after manufacture. After three successive ultracentrifugation and wash steps, $74 \pm 5 \%$ of IMQ was recovered in the liposome pellet, whereas in an IMQ control solution (not containing liposomes) the IMQ remained in the supernatant. That more IMQ was not recovered in the pellet most likely represents a limitation of the assay since negligible IMQ was present in the supernatant. Together, these results indicate that the majority of IMQ is localized in the lactic acid core of the liposomes. An unexpected result of IMQ incorporation in liposomes was the significantly higher particle size compared to liposomes containing GLA or liposomes without TLR agonists (Table 2), indicating that there may be some physicochemical interaction between the lipids and IMQ. The gradual decrease in $\mathrm{pH}$ over time is an important point that may be addressable through further liposome optimization. However, even if buffer exchange caused the internal $\mathrm{pH}$ of the liposomes to change enough to affect imiquimod solubility, the result could be the same type of 'coffee-bean' appearance that has been demonstrated for the FDA-approved liposome formulation of the cancer drug doxorubicin known as Doxil [39].

While IMQ loading efficiency is low (Table 1), it should be noted that the loading mechanism is passive rather than the more efficient, active loading methods based on $\mathrm{pH}$ or ammonium sulfate gradients [40], although some aqueous solubility is a prerequisite of such loading methods. By employing the mathematical model developed by Xu et al. [41], assuming $75 \mathrm{mM}$ phospholipid concentration, a monodisperse average particle size of $160 \mathrm{~nm}$ with polydispersity width of $\pm 35.2 \mathrm{~nm}$, a bilayer thickness of $4.8 \mathrm{~nm}$, and an average lipid molecular area of $0.4 \mathrm{~nm}^{2}$ [41,42], the expected passive encapsulation efficiency of IMQ is predicted to be $\sim 24 \%$. This may be overly optimistic considering that the Z-ave size value (i.e. $160 \mathrm{~nm}$ for IMQ-LS) is based on scattering intensity and thus biased towards larger particles, and does not represent the true number-based size mean which may be significantly smaller, thus reducing the expected encapsulation efficiency. Nevertheless, it should be possible to improve the loading efficiency of the liposomes in the present work with further process optimization.

In earlier work, we had demonstrated that GLA intercalated into phospholipid-emulsified oil at the oil/water interface, causing a more negative zeta potential $[38,43]$. The same technique applied to anionic liposomes is not as discriminatory due to the relatively high negative charge of the liposomes themselves [38]; nevertheless, given the insolubility of GLA and its affinity for phospholipid structures $[43,44]$, it is presumed that this TLR4 ligand localizes in the lipid bilayer in a similar manner to the other phospholipids. Moreover, in a previous report we employed in vitro bioactivity analysis and different orderof-mixing techniques to indicate that GLA formulated in anionic liposomes or oil-in-water emulsion is likely associated with the lipid particles rather than the bulk aqueous phase [45].

Ongoing work in our lab is seeking to enhance loading efficiency of liposomes containing IMQ by varying phospholipid concentration and liposome preparation techniques, such as replacing sonication with high pressure homogenization to achieve more reproducible and uniform particle size. However, even if loading efficiency remains somewhat low, the cost efficiency of IMQ-containing liposomes could still be quite favorable compared to other TLR7 ligands given that IMQ is available at approximately the same cost as phospholipid excipients (i.e. $<\$ 20 / g$ ) from generic manufacturers, which is not the case with newer imidazoquinoline-based TLR7 agonists.

Table 2 Comparison of liposome properties

\begin{tabular}{ccccccc}
\hline Liposome type & $\begin{array}{c}\text { Number of } \\
\text { batches }\end{array}$ & $\begin{array}{c}\text { Particle size } \\
\text { (Z-ave, nm) }\end{array}$ & $\begin{array}{c}\text { Polydispersity } \\
\text { index }\end{array}$ & $\begin{array}{c}\text { GLA retention } \\
\text { efficiency (\%) }\end{array}$ & $\begin{array}{c}\text { pH before buffer } \\
\text { exchange }\end{array}$ & $\begin{array}{c}\text { pH after buffer } \\
\text { exchange }\end{array}$ \\
\hline GLA-LS & 4 & $64 \pm 12$ & $0.23 \pm 0.05$ & $81 \pm 5$ & $2.54 \pm 0.06$ & $6.73 \pm 0.10$ \\
IMQ-LS* & 4 & $160 \pm 25$ & $0.21 \pm 0.10$ & - & $3.48 \pm 0.01$ & $6.84 \pm 0.10$ \\
GLA/IMQ-LS* & 4 & $141 \pm 5$ & $0.14 \pm 0.02$ & $79 \pm 10$ & $3.53 \pm 0.01$ & $6.92 \pm 0.01$ \\
LS & 4 & $70 \pm 25$ & $0.22 \pm 0.04$ & - & $2.60 \pm 0.05$ & $6.81 \pm 0.07$ \\
\hline
\end{tabular}

*These liposomes are part of the 8 total IMQ-containing liposomes represented in row 1 of Table 1. 


\section{Th1 responses in vivo}

Once well-characterized, liposomal adjuvants were available that contained GLA, IMQ, or both, their ability to mediate immune responses upon administration with the recombinant malaria antigen, PbCSP, was evaluated. The delivery system can potentially be used as an adjuvant for any appropriate vaccine, but we selected this malaria antigen as a model since we had had experience with adjuvanted formulations of this protein. While Th2 responses, as indicated by antigen-specific IL-5 secretion, were induced by immunization with empty or IMQ only-containing liposomes, these were reduced to essentially background levels with any GLA containing adjuvant (Figure 2). Thus, no difference could be seen in the ability to turn off IL- 5 between the GLA alone and the GLA + IMQ adjuvant. In contrast, both GLA containing adjuvants increased Th1 responses, as indicated by antigen-specific IFNY secretion. While the GLA alone liposomes resulted in robust secretion of IFN $\gamma$, the synergistic adjuvant was able to provide even higher IFN $\gamma$ responses (Figure 2).

To verify that the combination adjuvants resulted in a biologically active Th1 biased adaptive response, antibody responses were determined as a function of adjuvant (Figure 3). IgG1 in mice is reflective of a Th2 biased response and IgG2 is reflective of a Th1 bias. The trends seen with the antigen-specific spleen cell responses were reflected in the antibody responses: The adjuvants with TLR ligands gave more IgG2. The synergistic adjuvant gave the highest IgG2:IgG1 ratio consistent with the most Th1 biased immune response (Figure 3, Panel C).

\section{Conclusion}

We report here the development of a synergistic adjuvant that is manufacturable and combines TLR4 and TLR7 ligands. We were able to develop a process by
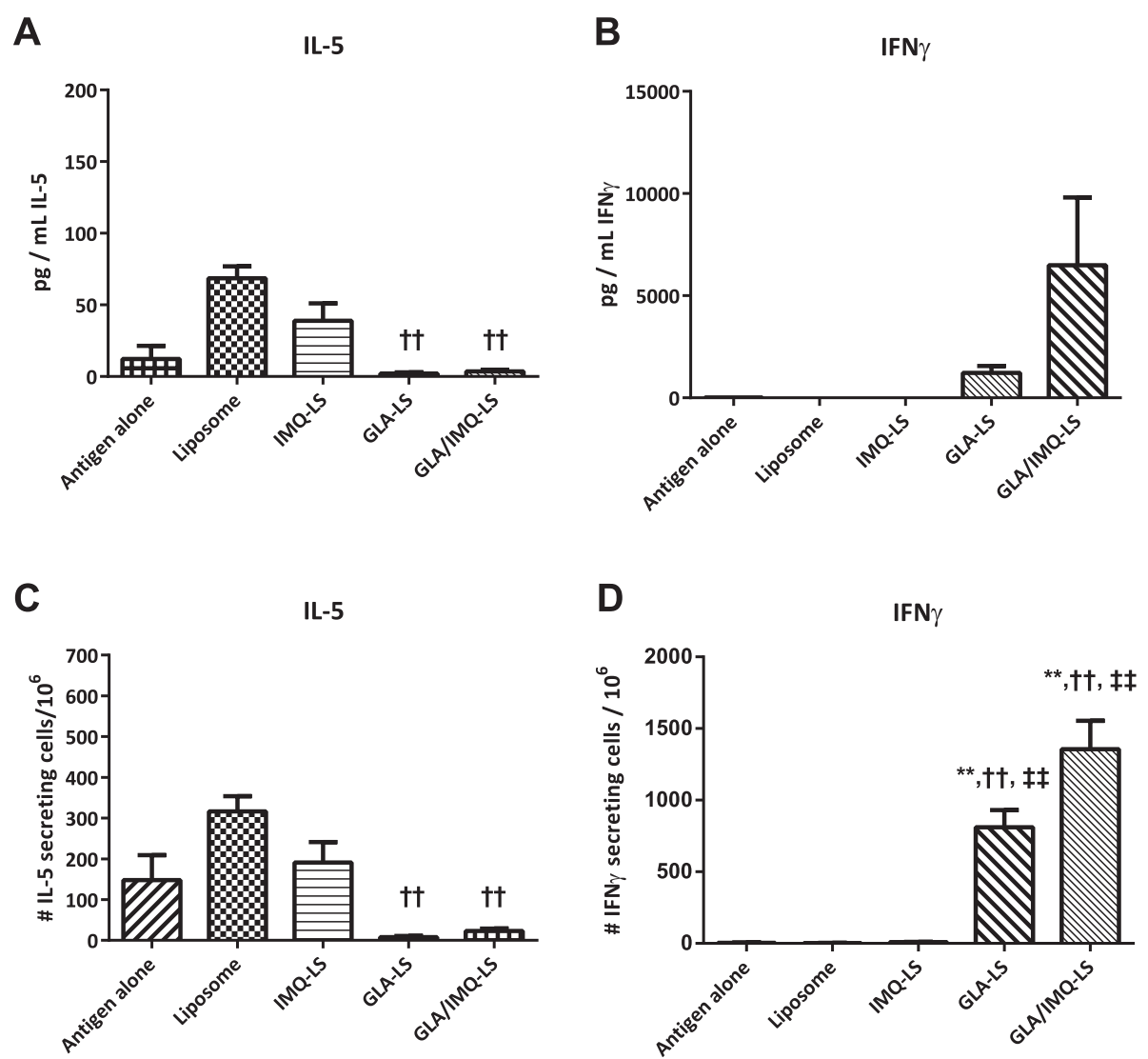

Figure 2 Synergy adjuvant enhances Th1 responses. Mice were immunized with either PbCSP antigen, the liposomal carrier, $20 \mu \mathrm{g} I \mathrm{MQ}$ in liposomes (IMQ-LS), $5 \mu \mathrm{g}$ GLA in liposomes (GLA-LS) or the combination adjuvant (5 $\mu \mathrm{g} / 20 \mu \mathrm{g}$, GLA/IMQ-LS), then spleen cells harvested and incubated with antigen. Panels A and B: ELISA determination of levels of secreted cytokines. Panels C and D: ELISPOT enumerations of the number of specific cytokine secreting cells. Significant differences between antigen alone, liposomes, IMQ liposomes, GLA liposomes, and IMQ/ GLA liposomes were observed for the IFNY ELISPOT ( $p$-value < 0.0001), IL-5 ELISPOT ( $p$-value $=0.0057$ ), and the IL-5 ELISA ( $p$-value $=0.0411)$. The differences for the IFNy ELISA did not reach statistical significance. Symbols: ${ }^{*}=$ significantly higher than Antigen alone; $+=$ significantly higher than Liposomes alone; $\neq=$ significantly higher than IMQ-LS; $\S=$ significantly higher than GLA-LS. Single symbol: $p<0.05 ;$ Double symbol: $p<0.01$; Shown are means with standard error. 

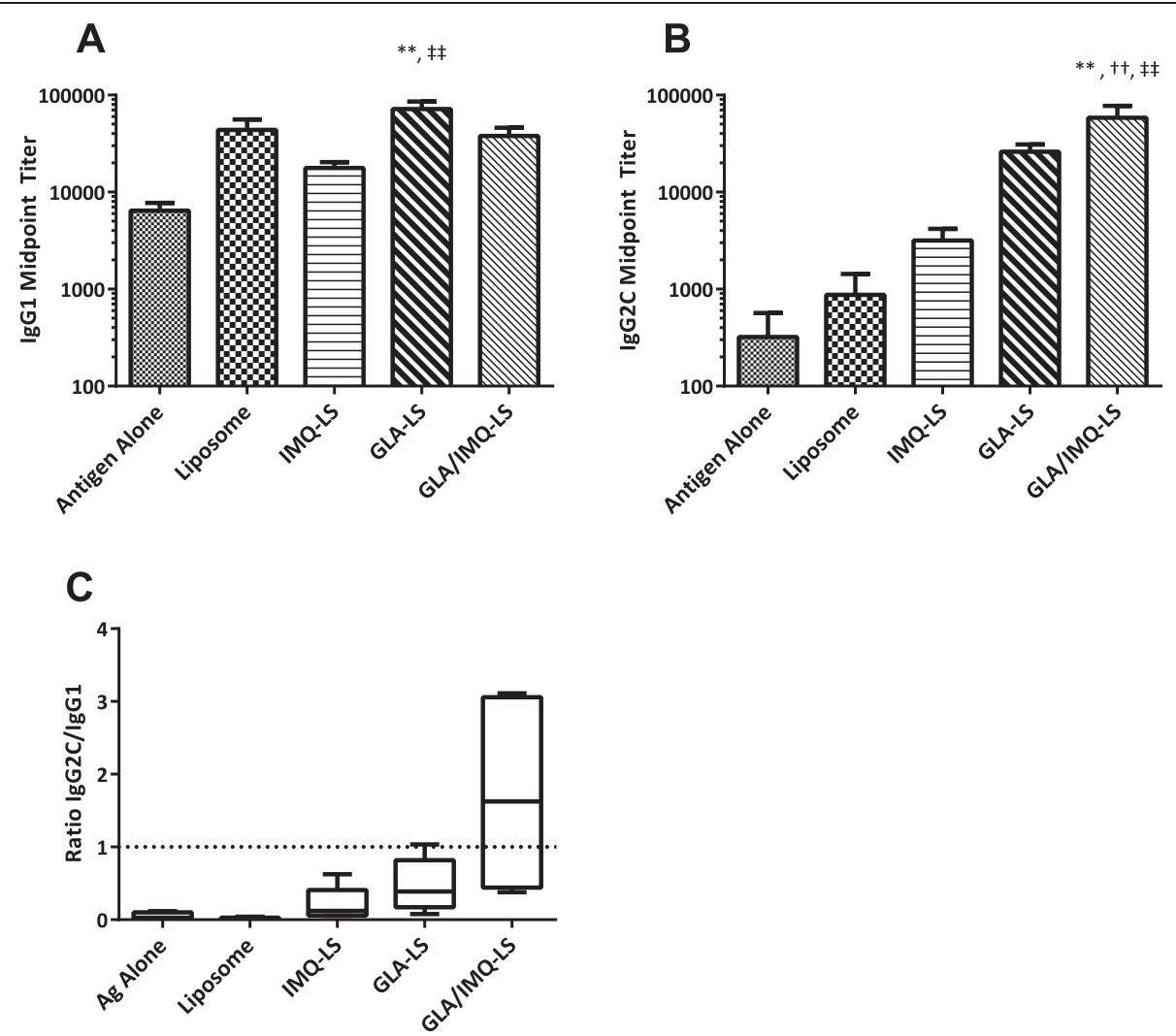

Figure 3 Adaptive humoral responses induced by synergy adjuvants. Sera were collected from mice after the second immunization and PbCSP antigen-specific lgG1 (Panel A) and lgG2C (Panel B) midpoint titers determined by ELISA. Consistent with the observed cytokine profile the combination induced higher levels of $\lg \mathrm{G} 2 \mathrm{C}$, a marker for Th1 immunity in mice. Panel $\mathbf{C}$ - the ratio in titers highlights the ability of the combination to induce Th1 biased immunity. ${ }^{*}=$ significantly higher than Antigen alone; $=$ significantly higher than Liposomes alone; $\neq=$ significantly higher than IMQ-LS; Single symbol: $p<0.05$; Double symbol: $p<0.01$. Shown are means with standard error.

which anionic liposomes could be made that incorporate the TLR4 ligand GLA at the phospholipid bilayer interface and the TLR7 ligand IMQ in their interior. The liposome co-localizes the agonists allowing same cell activation of the external sensor TLR4 through GLA and TLR7 through imiquimod. Therefore, the same cell would experience simultaneous triggering of two innate sensors, resulting in an enhanced cytokine response.

\section{Methods}

\section{Chemicals and reagents}

Milled imiquimod (IMQ) was purchased from Chemagis (Bnei Brak, Israel); imiquimod was also obtained from Invivogen (San Diego, CA). Glucopyranosyl lipid adjuvant (GLA), 1,2-dipalmitoyl-sn-glycero-3-phosphocholine (DP PC), 1,2-dipalmitoyl-sn-glycero-3-phosphoglycerol (DPPG), 1,2-dioleoyl-sn-glycero-3-phosphocholine (DOPC), and 1,2,dipalmitoyl-3-trimethylammonium-propane (DPTAP) were purchased from Avanti Polar Lipids Inc. (Alabaster, $\mathrm{AL}$ ). DOPC was also purchased from Lipoid (Newark, NJ). Cholesterol, and ammonium phosphate mono- and dibasic were purchased from J.T. Baker (San Francisco, CA). Lactic acid was purchased from Sigma-Aldrich (St. Louis, MO). Phosphate buffered saline (PBS) at pH 7.2 was purchased from Life Technologies (Grand Island, NY).

\section{Formulating liposomes}

Liposome formulations were manufactured by first combining phospholipids, cholesterol, and optionally, depending on the desired type of adjuvant, GLA, in chloroform: methanol or chloroform:methanol:water, which was then evaporated overnight using a Genevac EZ-2 Plus Evaporator (Stone Ridge, New York). The dried components were rehydrated in either $100 \mathrm{mM}$ lactic acid with or without $10 \mathrm{mg} / \mathrm{ml} \mathrm{IMQ}$, and then sonicated in a VWR 75D (West Chester, PA) or Crest Powersonic CP230D (Trenton, NJ) water batch sonicator at $\sim 60^{\circ} \mathrm{C}$ for $1.5-$ $3 \mathrm{hrs}$, until the formulation appeared homogeneous and translucent. This formulation was kept in a heated water bath prior to transferring $2.5 \mathrm{ml}$ to a separate disposable PD-10 desalting column obtained from GE Healthcare Bio-Sciences AB (Uppsala, Sweden). The columns arrived 
pre-packed with Sephadex G-25 medium and were primed and subsequently eluted with $3.5 \mathrm{ml}$ of PBS ( $\mathrm{pH} 7.2$ ). The buffer exchange step induces a $\sim 30 \% \mathrm{di}-$ lution of each formulation and is employed to exchange the bulk aqueous phase external to the liposomes from lactic acid to PBS, and to remove non-encapsulated IMQ. GLA-LS formulations were then mixed with GLA-IMQLS formulations in order to generate final formulations with different doses of IMQ.

\section{Characterizing the formulations}

Particle size of all liposomal formulations was monitored by dynamic light scattering (DLS) using the Malvern Instruments (Worcestershire, UK) Zetasizer Nano-S or Nano-ZS. Samples were prepared at 1:100 dilutions by combining $5 \mu \mathrm{l}$ of each formulation with $500 \mu \mathrm{l}$ of ultrapure water in a $1.5 \mathrm{ml}$ polystyrene disposable cuvette. DLS measurements were then made three times on each cuvette. Formulations containing GLA were analyzed by reverse-phase high performance liquid chromatography (HPLC) with charged aerosol detection (CAD) to determine GLA concentration as previously published [38] except that in some cases the column employed was a Waters XBridge C18 (Milford, MA). Formulations containing IMQ were analyzed by UV-vis spectroscopy (Hitachi U-3900H, Tokyo, Japan) to confirm IMQ concentration via absorbance at $307 \mathrm{~nm}$. The $\mathrm{pH}$ of the formulation before and after the buffer exchange was also measured. Liposome formulations containing IMQ were prepared in triplicates by combining $50 \mu \mathrm{l}$ of sample with $950 \mu \mathrm{l}$ of $\mathrm{EtOH} / \mathrm{HCl}(98 \% / 2 \%)$ into three separate disposable UV-cuvettes. IMQ concentration was extrapolated from a linear 5-point standard curve. $\mathrm{pH}$ was measured using a Mettler Toledo (Columbus, Ohio) MP225 pH meter and an Orion Ross semi-micro 8103BN $\mathrm{pH}$ probe obtained from Thermo Scientific (Waltham, MA). A 3-point calibration was performed prior to measurement with $\mathrm{pH} 4.00,7.00$, and 10.00 standard buffers. To determine whether IMQ was encapsulated in the liposomes, ultracentrifuged samples were prepared by transferring $200 \mu \mathrm{l}$ of the liposome formulation into a $1.5 \mathrm{ml}$ capacity ultracentrifuge tube and centrifuging at $160,000 \times \mathrm{g}^{\circ}$ at $4^{\circ} \mathrm{C}$ for three 3 -hour cycles using an Optima ${ }^{\text {тм }}$ MAX-XP Beckman-Coulter Ultracentrifuge (Indianapolis, IN). The supernatant was removed after each of the first two cycles and the pellet at the bottom of the tube was washed, each time with $1 \mathrm{ml}$ of PBS with gentle mixing, followed by another 3 hours of ultracentrifugation at $160,000 \times \mathrm{g}$ at $4^{\circ} \mathrm{C}$, and subsequent removal of the supernatant. The liposome pellet was then lysed with $1.05 \mathrm{ml}$ ethanol/concentrated hydrochloric acid (98\%/2\%), sonicated for $\sim 5$ mins, and diluted 1:20 in the same solvent mixture for spectrophotometric analysis.

\section{In-vitro stimulation using a whole blood assay (WBA)}

After obtaining informed consent, heparinized whole blood was collected from healthy volunteers and $180 \mu \mathrm{l}$ plated directly into 96-well round-bottom tissue culture plates. $20 \mu \mathrm{l}$ of each formulation with the various innate stimuli were then added giving final well volumes of $200 \mu \mathrm{l}$. Each stimulation condition was conducted in duplicate. IMQ from Invivogen was suspended in $\mathrm{dH}_{2} \mathrm{O}$ to a concentration of $5 \mathrm{mg} / \mathrm{ml}$. GLA-AF was manufactured as described in Orr et al. [38] at a concentration of $1 \mathrm{mg} / \mathrm{ml}$. IMQ and GLA were diluted in PBS prior to addition, either separately and in combination, to blood, which was then incubated at $37^{\circ} \mathrm{C}, 5 \% \mathrm{CO}_{2}$ for $24 \mathrm{~h}$. After incubation, $100 \mu \mathrm{l}$ of the plasma supernatant was carefully extracted and cytokine content measured by ELISA: Mip-1 $\beta$ (R \& D Systems, Minneapolis, MN); IL-8, IL-12p70, and IFNy (eBioscience, San Diego, CA).

\section{Mice and immunizations}

Plasmodium berghei circumsporozoite protein (PbCSP) was expressed and purified from E. coli using the codonharmonized construct kindly provided by Dr. Evelina Angov from the Walter Reed Army Institute of Research. All animal protocols were approved by the IDRI institutional animal care and use committee. Female C57BL/6 mice were purchased from Charles River Laboratories (Wilmington, MA) and maintained in specific pathogenfree conditions. Mice, 6-8 weeks of age, were immunized intramuscularly three times in two-week intervals by injection at the base of the tail. For immunization, recombinant protein was formulated with adjuvant to provide a total of $2 \mu \mathrm{g}$ protein/injection with various doses of the adjuvant in a total volume of $0.1 \mathrm{ml}$. The adjuvant doses corresponded to $20 \mu \mathrm{g}$ IMQ and $5 \mu \mathrm{g}$ GLA for both the single and combined adjuvants.

\section{Antibody analyses}

Blood was collected from the retro-orbital sinus two weeks after the second immunization and sera prepared. Sera were stored at $4^{\circ} \mathrm{C}$ until antigen-specific antibody responses were analyzed by ELISA. Briefly, ELISA plates (Nunc, Rochester, NY) were coated with $1 \mu \mathrm{g} / \mathrm{ml}$ antigen in $0.1 \mathrm{M}$ bicarbonate buffer and blocked with $0.1 \%$ BSAPBS. Following washes in PBS/Tween, serially diluted serum samples were added. After incubation and further washes, either anti-mouse IgG-HRP, anti-mouse-IgG2cHRP or anti-mouse IgG1-HRP were added (all Southern Biotech, Birmingham, AL). After incubation and washing, ABTS- $\mathrm{H}_{2} \mathrm{O}_{2}$ (Kirkegaard and Perry Laboratories, Gaithersburg, MD) was added to the plates to reveal any reactions, which were stopped by the addition of $0.1 \mathrm{~N}$ $\mathrm{H}_{2} \mathrm{SO}_{4}$. Plates were analyzed at $405 \mathrm{~nm}\left(\mathrm{EL}_{\mathrm{X}} 808\right.$, BioTek Instruments Inc, Winooski, VT). Midpoint titers 
were determined as EC50 values from weighted curve fits using the GraphPad Prism package V 6.03.

\section{Cell preparations and antigen stimulation assays}

Six weeks after the final immunization, spleens were removed and single cell suspensions prepared. Mononuclear cells were enumerated using a ViaCount assay with a PCA system (Guava Technologies, Hayward, CA). To determine overall cytokine production, spleen cells were cultured at $2 \times 10^{5}$ cells per well in duplicate in a 96-well plate (Corning Incorporated, Corning, NY) in RPMI-1640 supplemented with $10 \%$ heat-inactivated FCS and 50,000 Units penicillin/streptomycin (Invitrogen), in the presence of $10 \mu \mathrm{g} / \mathrm{ml}$ protein. Culture supernatants were harvested after 4 days and IFN $\gamma / \mathrm{IL}-5$ content determined by ELISA, according to the manufacturer's instructions (eBioscience, San Diego, CA).

To determine the number of cells producing each cytokine, multiScreen 96-well filtration plates (Millipore) were coated with rat anti-mouse IL- 5 or rat anti-mouse IFN $\gamma$ capture antibody (both eBioscience) and incubated overnight at $4{ }^{\circ} \mathrm{C}$. Plates were washed with PBS, blocked with RPMI 1640 and 10\% FBS for at least $1 \mathrm{~h}$ at room temperature, and washed again. Spleen cells were then added at $2 \times 10^{5}$ cells/well and stimulated with media or antigen $(10 \mu \mathrm{g} / \mathrm{ml})$ for $48 \mathrm{~h}$ at $37^{\circ} \mathrm{C}$. The plates were then washed with $0.1 \%$ PBS-Tween 20 and incubated overnight with a biotin-conjugated rat anti-mouse IL-5 or IFNY secondary antibody (eBioscience) diluted in 0.1\% PBS-Tween 20/0.5\% BSA. The filters were developed using the VectaStain $\mathrm{ABC}$ avidin peroxidase conjugate and Vectastain AEC substrate kits (Vector Laboratories, Burlingame, CA) according to the manufacturer's protocol. The reaction was stopped by washing the plates with deionized water. Plates were dried in the dark, and spots were counted on an automated ELISPOT reader (C.T.L. Series 3A Analyzer; Cellular Technology Ltd., Shaker Heights, $\mathrm{OH}$ ) and analyzed with ImmunoSpot software (Cellular Technology Ltd).

\section{Statistical methods}

Five mice were immunized for each treatment with two subsamples taken per mouse. These subsamples were handled by treating mice within each treatment as a nested random effect to allow the separation of the variability between mice from the variability within each mouse. In order to test Th1 and Th2 responses in vivo using ELISA determination of levels of secreted cytokines and ELISPOT enumerations of the number of specific cytokine screening cells for both IL-5 and IFNY secretions, four one-way ANOVA tests were used. Each test was used to compare mean differences between mice immunized with either antigen, the liposomal carrier, IMQ in liposomes, GLA in liposomes, or the combination adjuvant.
Tukey's procedure was used to test pairwise comparisons between treatments if significant treatment effects were found. Consideration of the variance estimates for the nested factor indicated that, in all cases, the majority of the variation in the data was due to variation between mice rather than variation among the subsamples taken from individual mice. All hypothesis testing was done at the $95 \%$ level.

\section{Abbreviations}

MPL: 3-O-desacyl-4'-monophosphoryl lipid A; IFN $\gamma$ : Interferon gamma; IL: Interleukin; MIP-1ß: Macrophage inflammatory protein 1-beta; TLR: TollLike Receptor; GLA: Glucopyranosyl lipid adjuvant; IMQ: Imiquimod.

\section{Competing interests}

The authors declare that they have no competing interests.

\section{Authors' contributions}

CF and SS performed the manufacturing and characterization studies. MD and JV performed the in vivo immunology; JG performed the cell-based assays. EM and DCo performed statistical analyses. DC and SR conceived of the study, and participated in its design and coordination and helped to draft the manuscript. All authors read and approved the final manuscript.

\section{Acknowledgements}

We thank Dr. Evelina Angov from the Walter Reed Army Institute of Research for providing the antigen used in these experiments, PbCSP. This research was supported with funding from the Bill and Melinda Gates Foundation, under grants 42387 and OPP1055855.

\section{Author details}

${ }^{1}$ Infectious Disease Research Institute (IDRI), Seattle, WA, USA. ${ }^{2}$ DFNet Research, Seattle, WA, USA. ${ }^{3}$ PAI Life Sciences, 1616 Eastlake Ave E Suite 500, Seattle 98102 WA, USA.

Received: 8 January 2014 Accepted: 14 April 2014

Published: 26 April 2014

\section{References}

1. Carter D, Reed SG: Role of adjuvants in modeling the immune response. Curr Opin HIV AIDS 2010, 5:409-413. 410.1097/COH.1090b1013e32833d32832cdb.

2. Ansong D, Asante KP, Vekemans J, Owusu SK, Owusu R, Brobby NAW, Dosoo D, Osei-Akoto A, Osei-Kwakye K, Asafo-Adjei E, Boahen KO, Sylverken J, Adjei G, Sambian D, Apanga S, Kayan K, Janssens MH, Lievens MJj, Olivier AC, Jongert E, Dubois P, Savarese BM, Cohen J, Antwi S, Greenwood BM, Evans JA, Agbenyega T, Moris PJ, Owusu-Agyei S: T cell responses to the RTS,S/ASO1<sub $>$ E $<$ /sub $>$ and RTS,S/ASO2 $<$ sub $>$ D $<$ /sub $>$ malaria candidate vaccines administered according to different schedules to Ghanaian children. PLoS One 2011, 6:e18891.

3. Harper DM, Vierthaler SL: Next generation cancer protection: the bivalent HPV vaccine for females. ISRN Obstet Gynecol 2011, 2011:457204.

4. Ray A, Cot M, Puzo G, Gilleron M, Nigou J: Bacterial cell wall macroamphiphiles: pathogen-/microbe-associated molecular patterns detected by mammalian innate immune system. Biochimie 2013, 95:33-42.

5. Meylan E, Tschopp J: Toll-like receptors and RNA helicases: two parallel ways to trigger antiviral responses. Mol Cell 2006, 22:561-569.

6. Hayashi F, Smith KD, Ozinsky A, Hawn TR, Yi EC, Goodlett DR, Eng JK, Akira S, Underhill DM, Aderem A: The innate immune response to bacterial flagellin is mediated by Toll-like receptor 5. Nature 2001, 410:1099-1103.

7. Song DH, Lee JO: Sensing of microbial molecular patterns by Toll-like receptors. Immunol Rev 2012, 250:216-229.

8. Johnson TR, Rao S, Seder RA, Chen M, Graham BS: TLR9 agonist, but not TLR7/8, functions as an adjuvant to diminish FI-RSV vaccine-enhanced disease, while either agonist used as therapy during primary RSV infection increases disease severity. Vaccine 2009, 27:3045-3052.

9. Park BS, Song DH, Kim HM, Choi BS, Lee H, Lee JO: The structural basis of lipopolysaccharide recognition by the TLR4-MD-2 complex. Nature 2009, 458:1191-1195. 
10. Lu YC, Yeh WC, Ohashi PS: LPS/TLR4 signal transduction pathway. Cytokine 2008, 42:145-151.

11. Gorski KS, Waller EL, Bjornton-Severson J, Hanten JA, Riter CL, Kieper WC, Gorden KB, Miller JS, Vasilakos JP, Tomai MA, Alkan SS: Distinct indirect pathways govern human NK-cell activation by TLR-7 and TLR- 8 agonists. Int Immunol 2006, 18:1115-1126.

12. Malhotra D, Relhan V, Reddy BS, Bamezai R: TLR2 Arg677Trp polymorphism in leprosy: revisited. Hum Genet 2005, 116:413-415.

13. Kawai T, Akira S: TLR signaling. Semin Immunol 2007, 19:24-32.

14. Miggin $S M, O^{\prime}$ Neill $L A$ : New insights into the regulation of TLR signaling. J Leukoc Biol 2006, 80:220-226.

15. Raman VS, Bhatia A, Picone A, Whittle J, Bailor HR, O'Donnell J, Pattabhi S, Guderian JA, Mohamath R, Duthie MS, Reed SG: Applying TLR synergy in immunotherapy: implications in cutaneous leishmaniasis. J Immunol 2010, 185:1701-1710.

16. Brosbol-Ravnborg A, Bundgaard B, Hollsberg P: Synergy between vitamin D3 and Toll-like receptor agonists regulates human dendritic cell response during maturation. Clin Dev Immunol 2013, 2013:807971.

17. Pone EJ, Zhang J, Mai T, White CA, Li G, Sakakura JK, Patel PJ, Al-Qahtani A Zan H, Xu Z, Casali P: BCR-signalling synergizes with TLR-signalling for induction of AID and immunoglobulin class-switching through the non-canonical NF-kappaB pathway. Nat Commun 2012, 3:767.

18. Coler RN, Bertholet S, Moutaftsi M, Guderian JA, Windish HP, Baldwin SL, Laughlin EM, Duthie MS, Fox CB, Carter D, Friede M, Vedvick TS, Reed SG: Development and characterization of synthetic glucopyranosyl lipid adjuvant system as a vaccine adjuvant. PLoS One 2011, 6:e16333.

19. Zhang WW, Matlashewski G: Immunization with a Toll-like receptor 7 and/ or 8 agonist vaccine adjuvant increases protective immunity against Leishmania major in BALB/c mice. Infect Immun 2008, 76:3777-3783.

20. Didierlaurent AM, Morel S, Lockman L, Giannini SL, Bisteau M, Carlsen H, Kielland A, Vosters O, Vanderheyde N, Schiavetti F, Larocque D, Van Mechelen M, Garcon N: AS04, an aluminum salt- and TLR4 agonist-based adjuvant system, induces a transient localized innate immune response leading to enhanced adaptive immunity. J Immunol 2009, 183:6186-6197.

21. El-On J, Bazarsky E, Sneir R: Leishmania major: in vitro and in vivo anti-leishmanial activity of paromomycin ointment (Leshcutan) combined with the immunomodulator imiquimod. Exp Parasito/ 2007, 116:156-162.

22. Kasturi SP, Skountzou I, Albrecht RA, Koutsonanos D, Hua T, Nakaya HI, Ravindran R, Stewart S, Alam M, Kwissa M, Villinger F, Murthy N, Steel J, Jacob J, Hogan RJ, Garcia-Sastre A, Compans R, Pulendran B: Programming the magnitude and persistence of antibody responses with innate immunity. Nature 2011, 470:543-547.

23. Wiley SR, Raman VS, Desbien A, Bailor HR, Bhardwaj R, Shakri AR, Reed SG, Chitnis CE, Carter D: Targeting TLRs expands the antibody repertoire in response to a malaria vaccine. Sci Transl Med 2011, 3:93ra69.

24. Ali OA, Verbeke C, Johnson C, Sands W, Lewin SA, White D, Doherty E, Dranoff $G$, Mooney DJ: Identification of immune factors regulating anti-tumor immunity using polymeric vaccines with multiple adjuvants. Cancer Res 2014, 74:1670-1681.

25. Shima F, Uto T, Akagi T, Akashi M: Synergistic stimulation of antigen presenting cells via TLR by combining CPG ODN and poly(gamma-glutamic acid)-based nanoparticles as vaccine adjuvants. Bioconjug Chem 2013, 24:926-933.

26. Yang M, Flavin K, Kopf I, Radics G, Hearnden CH, McManus GJ, Moran B, Villalta-Cerdas A, Echegoyen LA, Giordani S, Lavelle EC: Functionalization of carbon nanoparticles modulates inflammatory cell recruitment and NLRP3 inflammasome activation. Small 2013, 9:4194-4206.

27. Geeraedts F, Goutagny N, Hornung V, Severa M, de Haan A, Pool J, Wilschut J, Fitzgerald KA, Huckriede A: Superior immunogenicity of inactivated whole virus $\mathrm{H} 5 \mathrm{~N} 1$ influenza vaccine is primarily controlled by Toll-like receptor signalling. PLoS Pathog 2008, 4:e1000138

28. Schreibelt G, Benitez-Ribas D, Schuurhuis D, Lambeck AJ, van Hout-Kuijer M, Schaft N, Punt CJ, Figdor CG, Adema GJ, de Vries IJ: Commonly used prophylactic vaccines as an alternative for synthetically produced TLR ligands to mature monocyte-derived dendritic cells. Blood 2010, 116:564-574.

29. Invivogen: Imiquimod - R837 technical data sheet. 2013

30. Bachmann MF, Jennings GT: Vaccine delivery: a matter of size, geometry, kinetics and molecular patterns. Nat Rev Immunol 2010, 10:787-796.
31. Chollet JL, Jozwiakowski MJ, Phares KR, Reiter MJ, Roddy PJ, Schultz HJ, Ta QV, Tomai MA: Development of a topically active imiquimod formulation. Pharm Dev Technol 1999, 4:35-43

32. Hayashi T, Crain B, Corr M, Chan M, Cottam HB, Maj R, Barberis A, Leoni L, Carson DA: Intravesical Toll-like receptor 7 agonist R-837: optimization of its formulation in an orthotopic mouse model of bladder cancer. Int $\mathrm{J}$ Urol 2010, 17:483-490.

33. Falke J, Lammers RJ, Arentsen $H C$, Ravic M, Pozzi R, Cornel EB, Vergunst $H$, de Reijke TM, Witjes JA: Results of a phase 1 dose escalation study of intravesical TMX-101 in patients with nonmuscle invasive bladder cancer. J Urol 2013, 189:2077-2082.

34. Arentsen HC, de Kaa CA H-V, Jansen CF, Maj R, Leoni LM, Oosterwijk E, Witjes JA: Pharmacokinetics and toxicity of intravesical TMX-101: a preclinical study in pigs. BJU Int 2011, 108:1210-1214

35. Food and Drug Administration: Inactive ingredient search for approved drug products. U.S. Food and Drug Administration.

36. Alkan SS: Skills, knowledge, and translational technologies leading to novel vaccines. In Development of novel vaccines: skills, knowledge and translational technologies. Edited by Von Gabain A, Klade C. New York: Springer; 2006:1-2

37. Fransson J, Espander-Jansson A: Local tolerance of subcutaneous injections. J Pharm Pharmacol 1996, 48:1012-1015.

38. Orr MT, Fox CB, Baldwin SL, Sivananthan SJ, Lucas E, Lin S, Phan T, Moon JJ, Vedvick TS, Reed SG, Coler RN: Adjuvant formulation structure and composition are critical for the development of an effective vaccine against tuberculosis. J Control Release 2013, 172:190-200.

39. Barenholz Y: Doxil ${ }^{\oplus}$ - The first FDA-approved nano-drug: lessons learned. J Control Release 2012, 160:117-134.

40. Fenske DB, Maurer N, Cullis PR: Encapsulation of weakly-basic drugs, antisense oligonucleotides, and plasmid DNA within large unilamellar vesicles for drug delivery applications. In Liposomes: a practical approach. 2nd edition. Edited by Torchilin VP, Weissig V. New York: Oxford University Press; 2003.

41. Xu X, Khan MA, Burgess DJ: Predicting hydrophilic drug encapsulation inside unilamellar liposomes. Int J Pharm 2012, 423:410-418.

42. Edholm O, Nagle JF: Areas of molecules in membranes consisting of mixtures. Biophys J 2005, 89:1827-1832.

43. Anderson RC, Fox CB, Dutill TS, Shaverdian N, Evers TL, Poshusta GR, Chesko J, Coler RN, Friede M, Reed SG, Vedvick TS: Physicochemical characterization and biological activity of synthetic TLR4 agonist formulations. Coll Surf B: Biointerfaces 2010, 75:123-132.

44. Fox CB: Characterization of TLR4 agonist effects on Alhydrogel sedimentation: a novel application of laser scattering optical profiling. J Pharm Sci 2012, 101:4357-4364.

45. Misquith A, Fung HWM, Dowling QM, Guderian JA, Vedvick TS, Fox CB: In vitro evaluation of TLR4 agonist activity: formulation effects. Colloids Surf B: Biointerfaces 2014, 113:312-319.

doi:10.1186/1477-3155-12-17

Cite this article as: Fox et al: A nanoliposome delivery system to synergistically trigger TLR4 AND TLR7. Journal of Nanobiotechnology 2014 12:17

\section{Submit your next manuscript to BioMed Central and take full advantage of:}

- Convenient online submission

- Thorough peer review

- No space constraints or color figure charges

- Immediate publication on acceptance

- Inclusion in PubMed, CAS, Scopus and Google Scholar

- Research which is freely available for redistribution 